\title{
From the Editor-in-Chief
}

\section{Kimon P. Valavanis ${ }^{1}$}

Published online: 22 October 2018

(c) Springer Nature B.V. 2018

Dear Colleagues, readers and friends:

In this issue, I would like to report on a couple of logistical challenges with respect to scheduling issues and to 'pushing through' accepted papers. We recognize the importance of timely publication of issues. We understand that although papers appear online considerably before the printed issue, it is still important for authors to know where/when their paper will appear.

It is this challenge, given that we typically schedule accepted paper issues about one year in advance (sign of a healthy journal) that forces us to re-consider the frequency of Special Issues. The decision is to 'slow down a bit' and publish every paper currently in the acceptance queue, as of March 31, 2019, before we entertain the idea of a new Special Issue proposal. We believe this offers service to the authors, who deserve it, and to the readership of our journal. For the record, any new Special Issue proposal will be pushed after 2020, with publication date in 2021 .
Regardless, the plan is also to evaluate the JINT growth over the past years, look carefully at submission data and possibly consider increasing the number of pages per issue. This, will not affect quality, not at all. It will only allow us to publish accepted papers faster. Once we decide about it, you will be the first to know.

In the meantime, enjoy the issue.

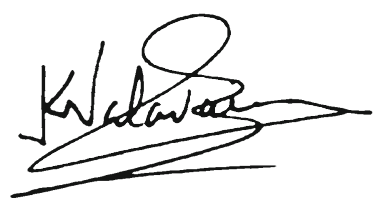

Kimon P. Valavanis Editor-in-Chief

Publisher's Note Springer Nature remains neutral with regard to jurisdictional claims in published maps and institutional affiliations.

Kimon P. Valavanis

Kimon.Valavanis@du.edu

1 D. F. Ritchie School of Engineering and Computer Science, University of Denver, Denver, CO 80208, USA 